\title{
Design and strength analysis of mechanical rack system
}

\author{
Mária Blatnická ${ }^{1,}$, Milan Sága ${ }^{1}$, Miroslav Blatnický ${ }^{2}$ \\ ${ }^{1}$ Department of Applied Mechanics, Faculty of Mechanical Engineering, University of Žilina, \\ Univerzitná 1, 01026 Žilina, Slovak Republic \\ ${ }^{2}$ Department of Transport and Handling Machines, Faculty of Mechanical Engineering, University of \\ Žilina, Univerzitná 1, 01026 Žilina, Slovak Republic
}

\begin{abstract}
The paper deals with a construction design of the rack system which will be used for storage of metallurgical rod material in a manufacturing engineering company. To meet requirements for manual control of the pull-out mechanism it will be determined the force exerted by the worker on the hand crank required to pull in and pull out the racking system at the full load. In addition, stress analysis was conducted by means of finite element method.
\end{abstract}

Keywords: Rack system, functional calculation, constructional design, stress analysis

\section{Introduction}

Storage cannot be separated from material flows in all spheres of economy. The need for storage of material of all kinds arises due to the different pace of production and consumption, the different flow in all levels of a logistic chain. Moreover, the storage forms an inevitable part of the production technology [1-3]. We can deal with warehouse issues in different ways, with reference to building solutions, the organization, technical equipment and many others. From the point of view of logistic objects it is particularly suitable to pay attention to three types of warehouses, namely the warehouse of bulk material, metallurgical material and pallets. Material characteristics, material amount, and storage technology requirements in connection with other processes are essential for the right choice of warehouses. In analysing the kind of metallurgical material in a certain engineering company (Fig. 1 left) it was found out that only $25 \%$ of items are material of one item in bulk with a large turnover rate of revenues and costs $[4,5]$. The rest of material weighed less though their items formed $70 \%$ up to $80 \%$ of the whole items in that warehouse. That's why it is necessary to provide with optimal conditions for storage and handling and at the same time it is simple to solve the technology of handled items offtake. Such piles of rod material are to be stocked in racks and we recommend to seize them by means of a grab bucket. Using this way of handling we do not need to bind material and in terms of controlling it is very suitable [6]. The engineering

\footnotetext{
${ }^{*}$ Corresponding author: maria.blatnicka@fstroj.uniza.sk

Reviewers: Michat Śledziński, Dominik Wilczyński
} 
company has to stock metallurgical material - rod material with the length of 5 meters, so for this reason it will be necessary to design the rack system with regard to customer's requirements.

\section{Construction design of rack system}

The construction design of steel construction consists of three elements (Fig. 1 right), i.e. bearing construction of central, vertical beams and horizontal beams, into which racks are pulled in and out, are welded to this construction. The storage method ensures demanded movement possibilities, i.e. the rack movement. The material in weight of 3000 kilos will be stored on eight retractable racks. Each retractable rack is divided into six parts - webs mutually connected with shafts by means of shaft coupling and they are pulled out together by a crank handle.
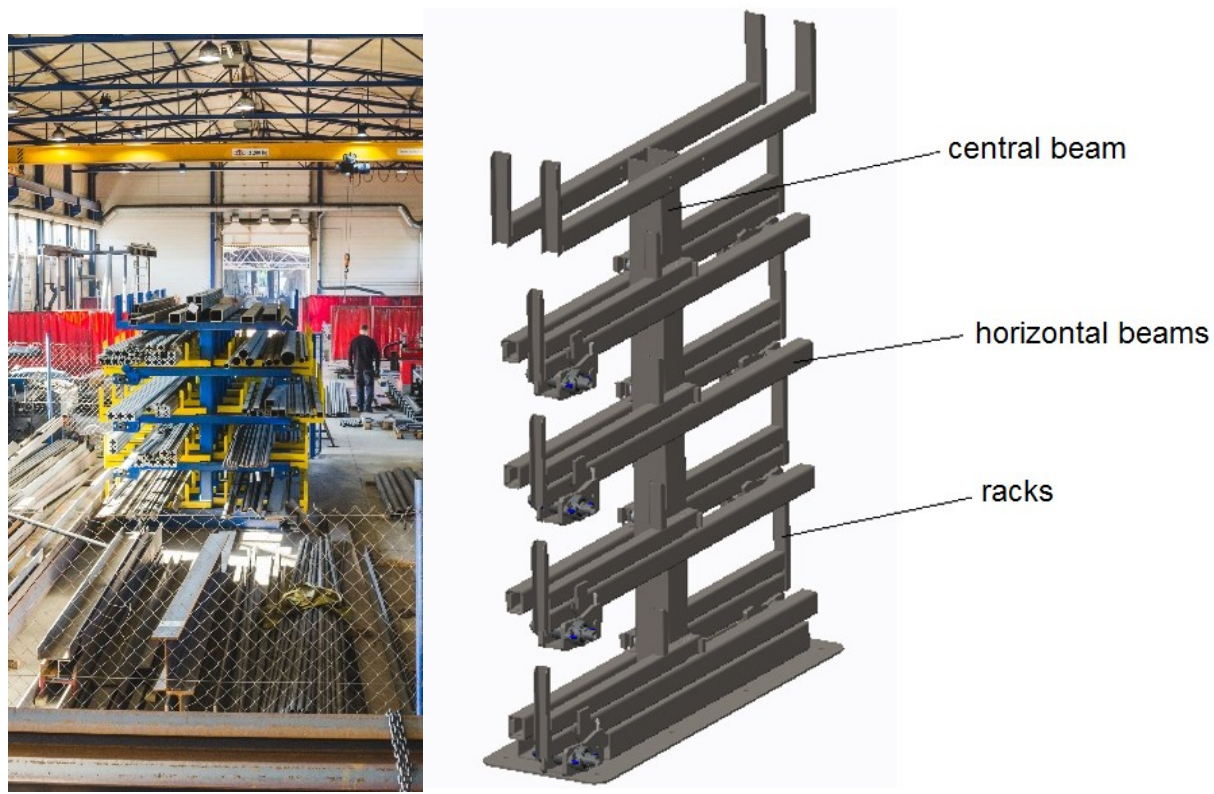

Fig. 1. Metallurgical material warehouse within a company (left) and $1 / 6$ model of rack system construction design (right)

Working with the $1 / 6$ model means to save calculation because the construction is designed symmetrically from the view of geometry, fixing and loading. The construction is made from thin-walled square tubing which dimensions and materials are put in Table 1.

Table 1. Construction parts

\begin{tabular}{|c|c|c|}
\hline structures & dimensions of square tubing & material \\
\hline central beam & $160 \times 160 \times 10$ & EN: S 235 (STN: 11 375) \\
\hline horizontal beams & $100 \times 80 \times 6$ & EN: S 355 (STN: 11523$)$ \\
\hline racks & $80 \times 60 \times 4$ & EN: S 355 (STN: 11523$)$ \\
\hline
\end{tabular}

Whereas the transmission of construction mechanism is driven by a crank handle, the racks will move forward at low speed, so the dynamic load of construction is not significant. We consider for material yield strength of horizontal beams and racks $R_{e}=360 \mathrm{MPa}$ and for coefficient of safety with regard to the static way of loading the construction $k=1.7$ (-). For 
material yield strength of central beams we consider $R_{e}=240 \mathrm{MPa}$ and for coefficient of safety with regard to the static way of loading the construction $k=1.7(-)$. Then for allowed stress in the construction by using material S 355 we get the amount $\sigma_{a l}=211 \mathrm{MPa}$ and for material S $235 \sigma_{a l}=141 \mathrm{MPa}$. In the place of weld of each construction parts it is necessary to decrease in the allowed stress of the amount which is experimentally practiced and decreases in the allowed stress of approximately $30 \%$ in the place of weld. We include this fact in the calculation by using the coefficient of the influence of welding $c=0,7(-)$. We get allowed amounts of stress in the place of welds for material S $355 \sigma_{a l w}=148 \mathrm{MPa}$ and for material S $235 \sigma_{a l w}=98 \mathrm{MPa}$. The realization of the mechanism for webs movement will be carried out by means of a friction wheel and we will expect low initial costs because its production technology is not really difficult. Moreover, there is no need for much maintenance because it is not necessary to lubricate, even it is not allowed. Another main advantage is a low frequency of failure rate.

Hand drive is not suitable for all constructions because we should take into account person`s performance and comfort [7-9]. We can use it only for a small load capacity, a low lift, and low working speeds during the occasional, not permanent use. When designing the hand drive, we have to remember that the permanent performance of an average person is about $75 \mathrm{~W}[10,11]$. And as well, we have to take into account the ergonomic point so that a worker can use the equipment without any difficulty. The best way of transferring power is by a handle at circular speed of maximum $1 \mathrm{~m} \cdot \mathrm{s}^{-1}$. During the permanent work of one worker (considering his performance) the force on the crank is set to the maximum of $100 \mathrm{~N}$. It is also possible to increase the force up to $200 \mathrm{~N}$ during 10 minutes, of course in case of reducing the speed [12-14]. Thus, the construction design of rack system is as follows (see Fig. 2).

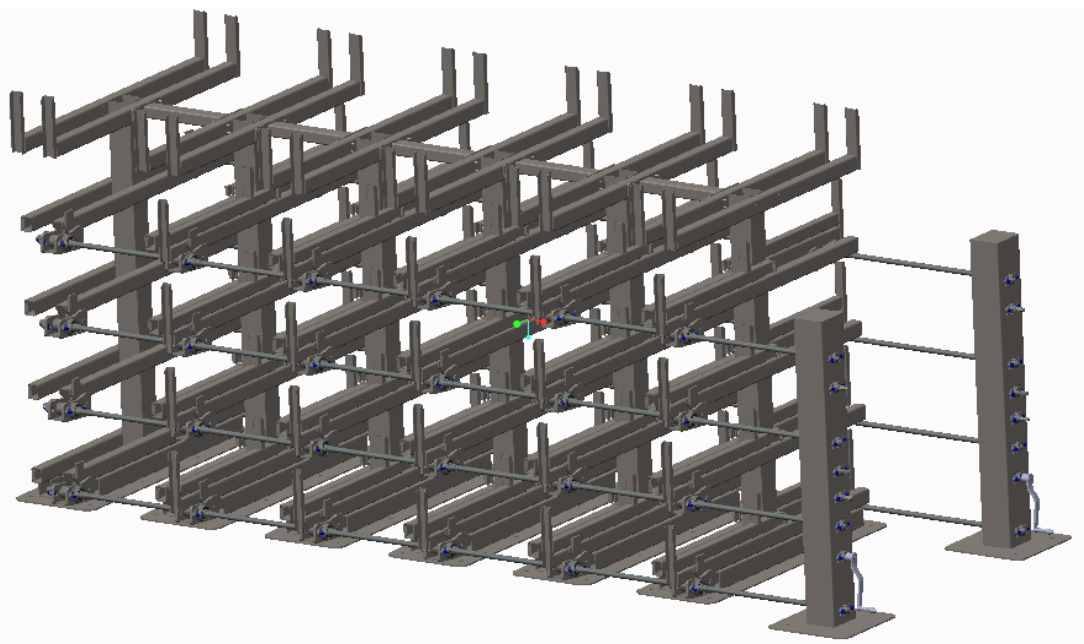

Fig. 2. 3D model of the designed rack system with pull-out webs

\section{Rack pull-out mechanism operating principle}

In Figure 3 we can see a scheme of a rack part with the pull-out friction mechanism. There is material put on the upper square tubing (1). This upper and as well lower square tubing (2) is pulled out by means of the friction wheel (3). The wheel (3) is firmly connected with the shaft (7) which is driven through the chain transmission (8) by means of the hand crank (9). The lower square tubing (2) is put into the larger square tubing (6). While pulling out the upper bearing (4) helps the movement and it is moving on the surface of the square tubing (6) without touching of the lower bearing (5) with the inner surface of the square tubing (6). 
With pulling in of the rack the lower bearing (5) helps, it moves on the inner surface of the square tubing (6) and the upper bearing does not touch the square tubing surface (6).

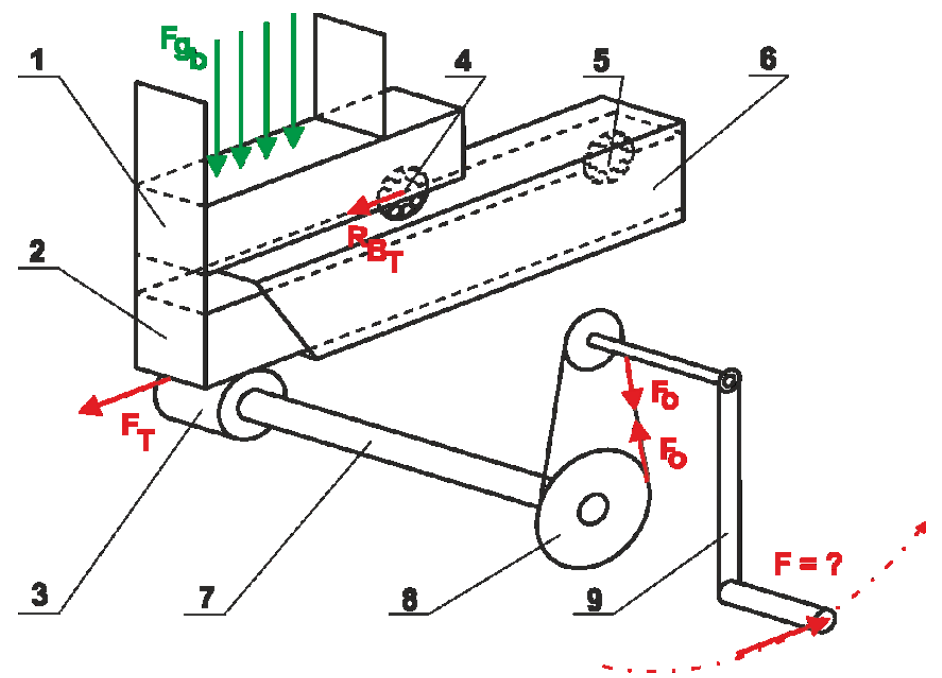

Fig. 3. The schematic design of the rack pull-out mechanism

Supposing low working speeds and smooth motion we did not pay attention to dynamic effects while designing the mechanism, so we simplified the dynamic model and designed the static model. The mechanism is released into two positions because of having two extreme positions. One position is when the rack is pull-in and it is needed to be pulled out. In Figure 4 on the left forces and reactions are described in the beginning of pulling out the rack. We suppose that the force which releases the mechanism into motion will be greater than the force which is needed to keep it in motion, because the slide friction coefficient is greater in stillness than in motion. We also take into account the other situation when the rack is pulled in from the fully pull-out position. Then the reactions will be different, as it is seen in Figure 4 on the right.

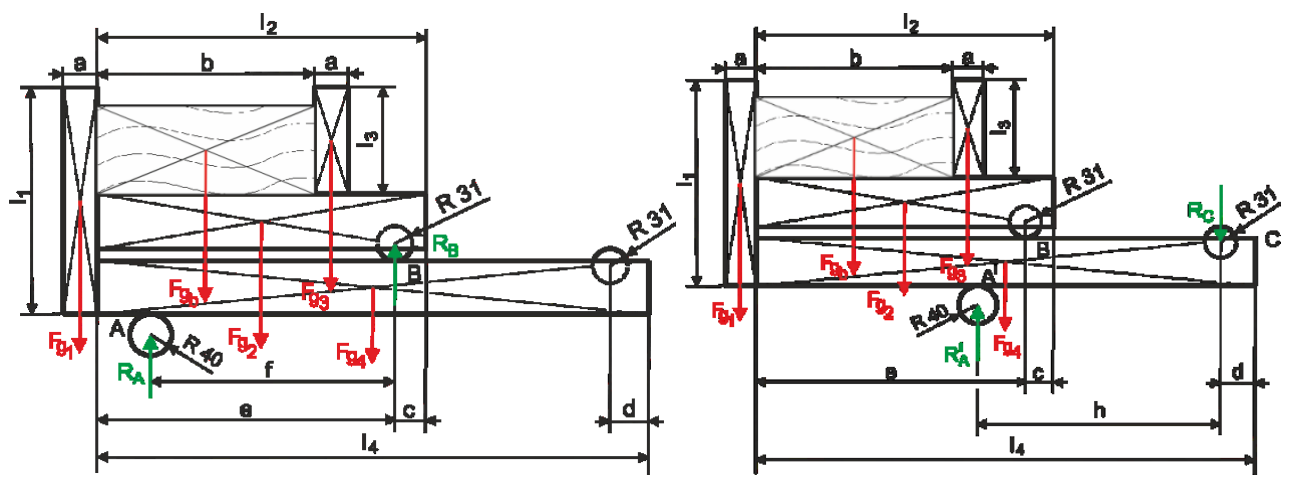

Fig. 4. Releasing of the mechanism for pulling out (on the left) and pulling in (on the right)

The Table 2 presents data relating to mechanism parts and they were used during calculations. 
Table 2. Values of the rack mechanism geometry

\begin{tabular}{|c|c|c|c|}
\hline $\mathrm{a}$ & $40 \mathrm{~mm}$ & $\mathrm{f}$ & $958 \mathrm{~mm}$ \\
\hline $\mathrm{b}$ & $900 \mathrm{~mm}$ & $1_{1}$ & $400 \mathrm{~mm}$ \\
\hline $\mathrm{c}$ & $82 \mathrm{~mm}$ & $1_{2}$ & $1200 \mathrm{~mm}$ \\
\hline $\mathrm{d}$ & $103 \mathrm{~mm}$ & $1_{3}$ & $200 \mathrm{~mm}$ \\
\hline $\mathrm{e}$ & $1118 \mathrm{~mm}$ & $1_{4}$ & $2095 \mathrm{~mm}$ \\
\hline
\end{tabular}

After calculating on the values of load forces in the mechanism, i.e. weight forces from load and weight of the moving parts of the construction, it is possible to determine important reactions in the friction wheel and auxiliary wheel $\mathrm{B}$ in the pull-out position, and reactions in the friction wheel and auxiliary wheel $\mathrm{C}$ in the pull-in position. The values of weight forces of a rack result from linear mass density of used tubing and values of weight acceleration. The effects of forces are: $F_{g 1}=19.29 \mathrm{~N}, F_{g 2}=115.72 \mathrm{~N}, F_{g 3}=9.64 \mathrm{~N}, F_{g 4}=202.03 \mathrm{~N}$ a $F_{g b}=4905 \mathrm{~N}$.

\section{Functional calculation of the force on the hand crank}

Based on simple statics equations and Fig. 4 we get:

$R_{A}=3520.86 \mathrm{~N}$,

$R_{B}=1730.82 \mathrm{~N}$,

$R_{A}{ }^{\prime}=8685.42 \mathrm{~N}$,

$R_{C}=3433.74 \mathrm{~N}$.

From the reaction on the friction wheel $R_{A}$ (pulling out) and $R_{A}$ ' (pulling in) we count the needed tensile force $F_{T}$.

$$
F_{T}=R_{A} \cdot \frac{\xi}{d_{K}} .
$$

The diameter of the driven friction wheel is $d_{K}=80 \mathrm{~mm}$ and the rolling resistance arm $\xi$ in the supposed diameter of the friction wheel and material of kinematic pair (steel-steel) we choose $\xi=0.5 \mathrm{~mm}$. By putting the appropriate values into the equation (5) we get the amount of friction force in pulling out the mechanism $F_{T 1}=22 \mathrm{~N}$ and in pulling in the mechanism the tensile force $F_{T 2}=54.28 \mathrm{~N}$. Not to slide the tubing on the surface of the wheel, one condition must be secured, i.e. the static condition of rolling (6):

$$
F_{T t} \geq F_{T},
$$

where $F_{T t}=R_{A} \cdot f$ is the tensile force supposed the sliding and $\mathrm{f}$ is the coefficient of slide friction, thus (7):

$$
R_{A} \cdot f \geq R_{A} \cdot \frac{\xi}{d_{K}}
$$

Resulting in (8):

$$
d_{K} \geq \frac{\xi}{f}
$$

After putting numeric values we get $80 \mathrm{~mm}>5 \mathrm{~mm}$ and the condition of rolling is fulfilled without sliding and increasing of needed tensile force. Then it is necessary to count the tensile force (9) on the bearing B (pulling out) and C (pulling in), which serve to facilitate movement (there is rolling resistance instead of the slide friction):

$$
R_{B_{T}}=R_{B} \cdot \frac{\xi}{r_{L}} .
$$

When we put real values into the equation (9): $r_{L}=31 \mathrm{~mm}$ the radius of the auxiliary wheel constructed as roller bearing and $\xi=0.005 \mathrm{~mm}$ is for rolling resistance arm, so we get $R_{B T}=0.28 \mathrm{~N}$ for the tensile force in the bearing $\mathrm{B}$. We can use the same equation for the 
calculation of the tensile force in the bearing $\mathrm{C}$ by means of appropriate values. For the tensile force in the bearing $\mathrm{C}$ we get $R_{C T}=0.55 \mathrm{~N}$. The total force needed for pulling out and in of the rack part will be given by the force on the bearing and by the tensile force on the driving friction wheel increased by the loss $\eta$ in placing (10):

$$
F_{C 1}=R_{B_{T}}+\frac{F_{T 1}}{\eta \cdot \eta}
$$

Placing is carried out by means of two rotary couplings on the roller bearings, each with the medium efficiency $\eta=0.98(-)$. When we put the values into the equation (10) we get the amount of total force in pulling out $F_{C l}=23.19 \mathrm{~N}$ and pulling in $F_{C 2}=57.01 \mathrm{~N}$. This value needs to be increased six times because the calculation was carried out by means of the sixths model with the sixths load. Then the total force in pulling out is $F_{l}=139.14 \mathrm{~N}$ and in pulling in $F_{2}=342.06 \mathrm{~N}$. These forces are still too great for the arms to be pulled out and in by a hand. That is why we add a chain transmission between the arms and the crank handle. The torsion moment of the friction wheel must be as great as the torsion moment of the big chain wheel (without considering the losses). When we analyse both moments and put the efficiency of the chain wheel into the calculation, in the chain of the chain transmission we get for the force $F_{O I}$ when pulling out and $F_{O 2}$, when pulling in (11):

$$
\begin{aligned}
& F_{O 1}=\frac{F_{1} \cdot r_{K}}{\eta_{K} \cdot r_{v}}, \\
& F_{O 2}=\frac{F_{2} \cdot r_{K}}{\eta_{K} \cdot r_{v}} .
\end{aligned}
$$

In the equation (13) $r_{K}$ is the friction wheel radius $r_{K}=40 \mathrm{~mm}, \eta_{K}$ is the efficiency of the chain wheel $\eta_{K}=0.94(-), r_{V}$ is the big chain wheel radius $r_{V}=60 \mathrm{~mm}, F_{O 1}$ is the force inside the chain while pulling out, $F_{O 2}$ is the force inside the chain while pulling in. When we put the values into the equation (11), we get $F_{O 1}=98.68 \mathrm{~N}$ and $F_{O 2}=242.6 \mathrm{~N}$. Then we also consider the moment equilibrium. The torsion moment of the small chain wheel must be equal to the torsion moment of the crank. When we analyse the moments and include all efficiency, we get the amount of force which must be used on the crank for the rack to be pulled out $F_{v}$ and pulled in $F_{z}$ (12):

$$
\begin{aligned}
& F_{1}=\frac{F_{O 1} \cdot r_{m}}{\eta \cdot R}, \\
& F_{2}=\frac{F_{O 2} \cdot r_{m}}{\eta \cdot R} .
\end{aligned}
$$

In the equation (14) $r_{m}$ is the radius of the small chain wheel: $r_{m}=30 \mathrm{~mm}, \eta_{K}$ is efficiency of the chain wheel $\eta_{K}=0.94(-), \mathrm{R}$ is the radius of the crank and we choose $\mathrm{R}=300 \mathrm{~mm}, F_{1}$ is the force needed for the crank when pulling out the rack, $F_{2}$ is the force needed for the crank when pulling in the rack. Putting the values in the equation (12), we get for $F_{1}=10.5 \mathrm{~N}$ and for $F_{2}=25.8 \mathrm{~N}$. So it is obvious that the forces $F_{l}$ and $F_{2}$ are low enough so that the worker is able to develop them on the crank.

\section{Stress analysis of the rack system}

The strength analysis of the rack system will be carried out in the program ADINA by using the finite element method (FEM) $[15,16]$. As the construction consists of thin-walled tubing, it is suitable for the model to be constructed from shell elements [17]. In ADINA Structures Pre-Processing we created the geometry of the shell model of the rack bearing part and the geometry of the arm shell model $[18,19]$.

Similarly, like dealing with the forces on the crank, we will solve it and divide it into two parts. The mechanism can be placed in two extreme positions when the rack is pulled-in (Fig. 5) or pulled-out (Fig. 6). 

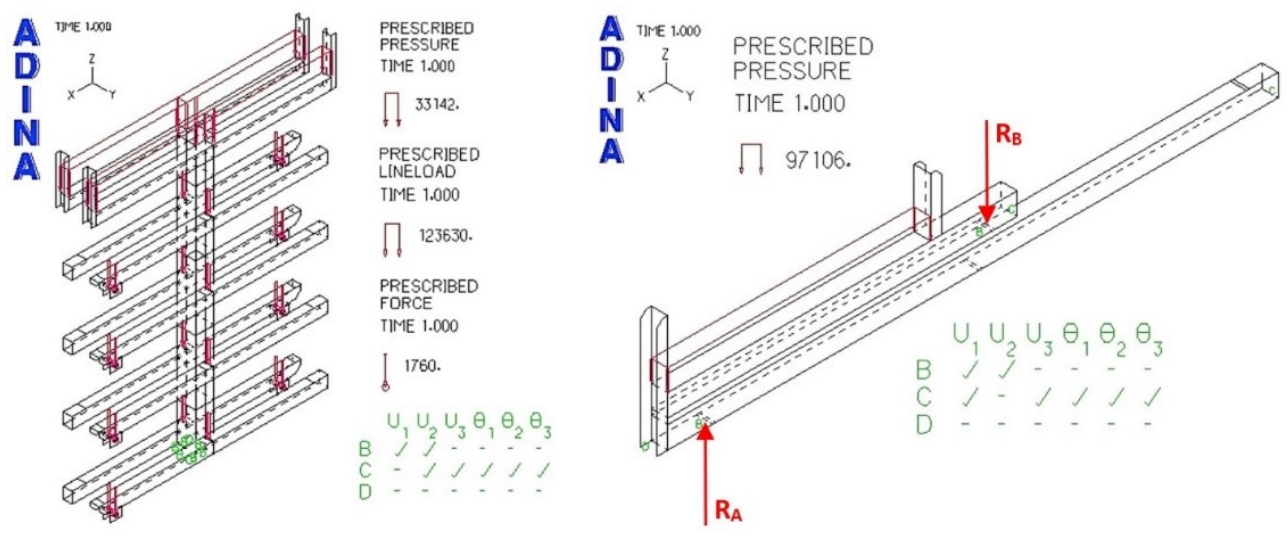

Fig. 5. Limits of loaded pulled-in rack system
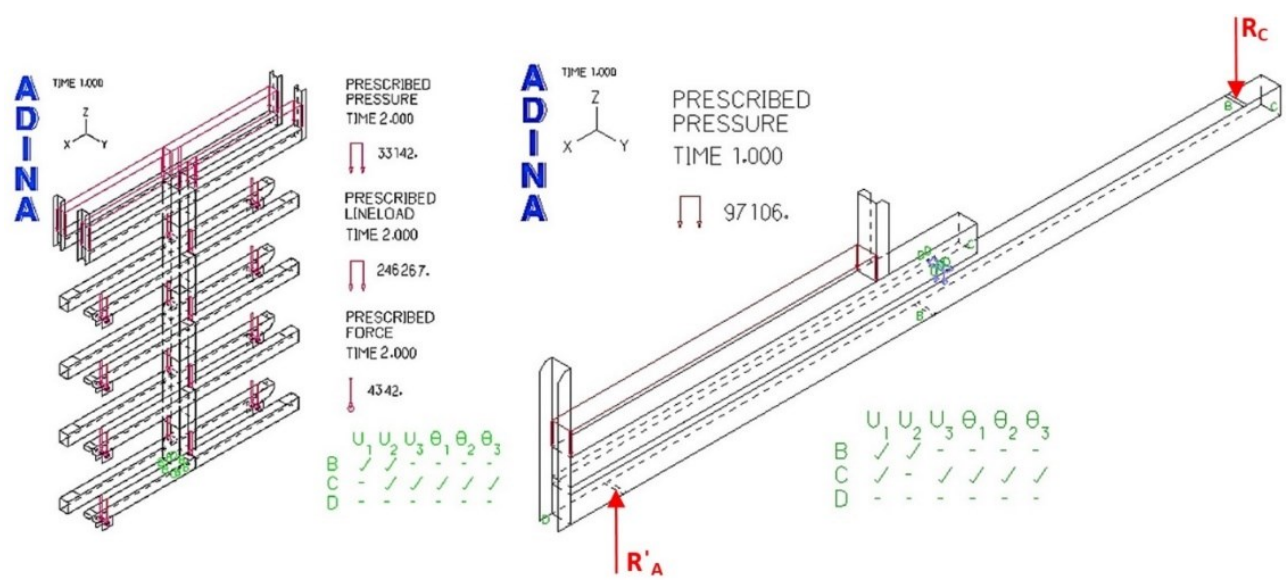

Fig. 6. Limits of loaded pulled-out rack system

As seen in Fig. 7 on the left, in the pulled-in position of the racks the maximum smoothed stress in the load bearing construction is $86.67 \mathrm{MPa}$, except for the point of the attachment.

The simulating value is smaller than the allowed stress in the welded construction that is $98 \mathrm{MPa}$. So for the pulled-in position the rack system is set properly. As seen in Fig. 7 on the right, the maximum smoothed stress of the rack arm is $57.09 \mathrm{MPa}$.
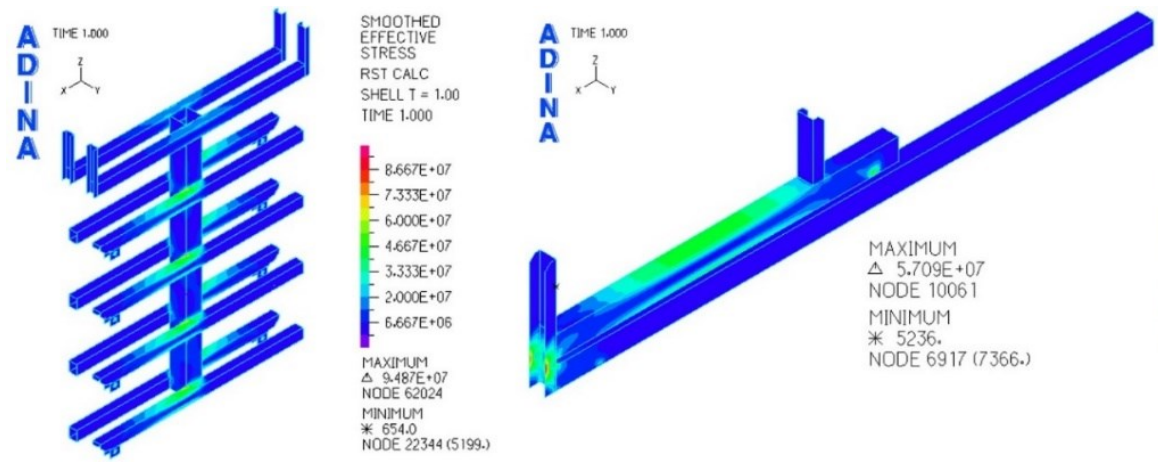

SMOOTHED
EFFECTIVE EFFECTIVE
STRESS RST CALC SHELL $T=1.00$
TIME 1.000

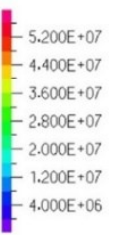

Fig. 7. Smoothed stress in the rack part (on the left) and rack arms (on the right) in the pulled-in position 
We will not take into account this value because the stress is at the point of applying the boundary condition. The stress according to the colour scale in the picture is important. It is $52 \mathrm{MPa}$, which in comparison with permitted stress $(211 \mathrm{MPa})$ for the non-welded material (the maximum of the stress is not in the point of the weld) will prove the correctness of the construction design [20].
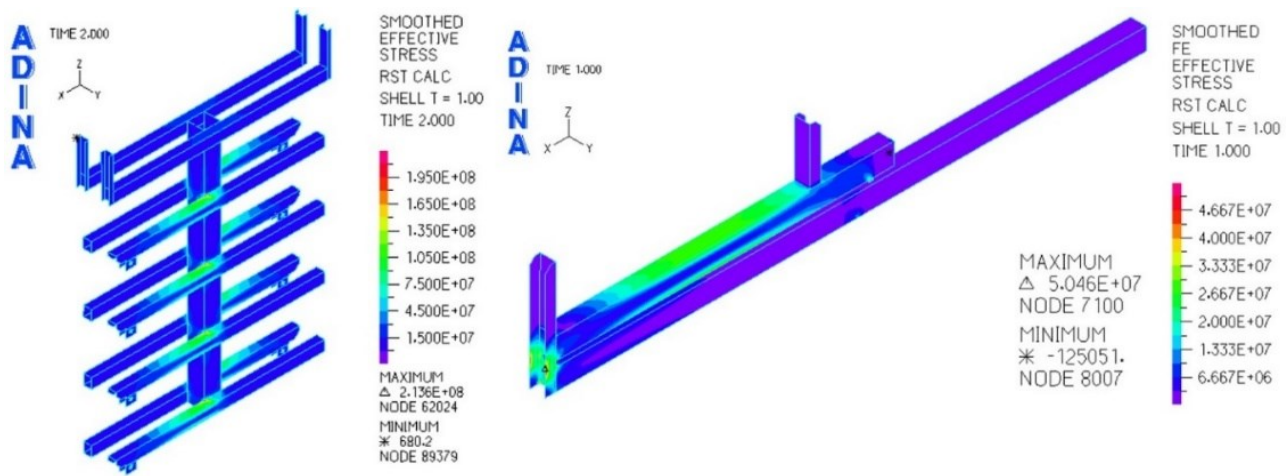

Fig. 8. Smoothed stress in the rack part (on the left) and rack arms (on the right) in the pulled-out position

In time $t=2 \mathrm{~s}$, i.e. in pulled-out position of racks, the bearing construction is in the stress according to Fig. 8 on the left. As it can be seen in Fig. 8 on the left, the maximum of the smoothed stress is $213.6 \mathrm{MPa}$ in the point of the attachment. The stress in the weld is $195 \mathrm{MPa}$. We cannot use the strength condition because the calculated stress (195 MPa) is bigger than the permitted stress in weld $(98 \mathrm{MPa})$. On the other hand we can use the strength condition for the rack arm in the pulled-out and pulled-in position. The maximum of the simulating stress (approx. $50 \mathrm{MPa}$ ) is suitable.

\section{Conclusion}

The aim of this article was the design and strength analysis of the rack with pull-out arms intended for using in an engineering company for steel tubes storage. We described the theoretical aspects of steel constructions, which helped to achieve the objectives. The pullout rack analysis has proved that this part of the construction meet the safety requirements while loading the pull-out or pull-in rack positions. The analysis of the bearing construction showed significant deficiencies in strength and stability of the pulled-out rack position when the welds had the stress 213.6 MPa. Therefore, design modification has to be done in the next step of addressing this issue.

This work has been supported by KEGA project No. 015ŽU-4/2017.

\section{References}

1. R. Halama, M. Fusek, Z. Poruba, Influence of mean stress and stress amplitude on uniaxial and biaxial ratcheting of ST52 steel and its prediction by the AbdelKarim-Ohno model. International Journal of Fatigue 91, 313-321 (2016)

2. J. Gerlici, T. Lack, J. Harušinec, Realistic simulation of railway operation on the RAILBCOT test stand. Applied mechanics and materials 486, 387-395 (2014)

3. A. Sapietová, V. Dekýš, M. Sapieta, P. Pecháč, Application of computational and design approaches to improve carrier stability. Procedia Eng. 96, 410-418 (2014) 
4. J. Czerniak, D. Ewald, M. Macko, G. Śmigielski, K. Tyszczuk, Approach to the Monitoring of Energy Consumption in Eco-grinder Based on ABC optimization, in: S. Kozielski et al. (Eds.): BDAS 2015, Communications in Computer and Information Science 521, Springer International Publishing Switzerland, 516-529, (2015)

5. P. Št'astniak, M. Moravčík, Freight bogie prototype properties analysis by means of simulation computations. Manufacturing technology 17 (3), 381-388 (2017)

6. G. Domek, A. Kołodziej: Design of the tendon structure in timing belts Procedia Engineering 136, 365-369 (2016)

7. J. Galliková, R. Poprocký, P. Volna, Implementation of FMEA method in maintenance of semi-trailer combination. Diagnostyka 17 (4), 85-92 (2016)

8. M. Macko, J. Flizikowski, Z. Szczepański, K. Tyszczuk, G. Śmigielski, A. Mroziński, J. Czerniak, A. Tomporowski, CAD/CAE applications in mill's design and investigation. Proceedings of the 13th International Scientific Conference on Computer Aided Engineering - Editors: Rusinski, Eugeniusz, Pietrusiak, Damian (Eds.). Series Title: Lecture Notes in Mechanical Engineering. Chapter 35 - DOI: 10.1007/978-3-319-509389_35. ISBN: 978-3-319-50937-2, Springer International Publishing AG https://link.springer.com/chapter/10.1007/978-3-319-50938-9_35, 343-351 (2017)

9. J. Vavro jr., J. Vavro, P. Kováčiková, P. Kopas, M. Handrik, R. Bezdedová, Numerical analysis of stress states for graphitic cast iron structures. Applied Mechanics and Materials 611, 252-255 (2014)

10. J. Gerlici, T. Lack, Railway wheel and rail head profiles development based on the geometric characteristics shapes. Wear: an international journal on the science and technology of friction, lubrication and wear 271 (1-2) Sp. iss., 246-258 (2011)

11. G. Śmigielski, W. Toczek, R. Dygdała, K. Stefański, Metrological analysis of precision of the system of delivering a water capsule for explosive production of water aerosol. Metrology and Measurement Systems, 23 (1), 47-58 (2016)

12. M. Sapieta, A. Sapietová, L. Gajdoš, Determine the fatigue life of flange of bearings test station. Procedia Engineering 177, 548-553 (2017)

13. R. Halama, M. Fusek, F. Fojtík, An industrial application of a method for spatial motion measurement. EAN 2010: 48th International Scientific Conference on Experimental Stress Analysis, 75-80 (2010)

14. M. Handrik, M. Vaško, P. Kopas, V. Mozer, The linear and nonlinear stability loss of structures due to thermal load. Procedia Engineering 136, 359-364 (2016)

15. J. Vavro, J. Vavro jr., P. Kováčiková, P. Kopas, M. Handrik, Simulation and analysis of defect distribution in passenger car tire under dynamic loading. Applied Mechanics and Materials 611, 544-547 (2014)

16. M. Dudziak, G. Domek, A. Kołodziej, K. Talaśka, Contact Problems Between the Hub and the Shaft with a Four-Angular Shape of Cross-Section for Different Angular Positions. Applied Mechanics and Materials 816, 54-62 (2015)

17. P. Krawiec, Numerical Analysis of Geometrical Characteristics of Machine Elements Obtained Through CMM Scanning. Progress in Industrial Mathematics, Springer-Verlag, Berlin-Heidelberg, 925-930 (2010)

18. V.P. Mateichyk, V.P. Volkov, P.B. Komov, I.V. Gritsuk, et al., Special features of vehicle condition monitoring using onboard diagnostics systems. Project management, systems analysis and logistics: Scientifc journal, K.: NTU, 13, 126-138, (2014) 
19. Y. Turygin, P. Božek, I. V. Abramov, Y. Nikitin, Reliability determination and diagnostics of a mechatronic system. In Advances in Science and Technology Research Journal. Vol. 12, Iss. 2, 274-290, ISSN (2018)

20. E. Kalentev, Š. Václav, P. Božek, A. I. Korshunov, V. Tarasov, Numerical analysis of the stress-strain state of a rope strand with linear contact under tension and torsion loading conditions. In Advances in Science and Technology Research Journal. Vol. 11, iss. 2, 231-239, ISSN 2299-8624, DOI: 10.12913/22998624/71181 (2017) 